Article

\title{
Improving Care for Spanish-Speaking Older Adults with Breast Cancer: Feasibility, Reliability, and Validity of a Self-Administered Spanish Language Geriatric Assessment
}

\author{
Enrique Soto-Perez-de-Celis ${ }^{1}$ (D) Jessica Vazquez ${ }^{2}$, Heeyoung Kim ${ }^{2}$, Can-Lan Sun ${ }^{2}$, Kemeberly Charles ${ }^{2}$, \\ Ashley Celis ${ }^{2}$, Vani Katheria ${ }^{2}$, Daneng Li ${ }^{2}$, William Dale ${ }^{2}$ and Mina S. Sedrak ${ }^{2, *(1)}$ \\ 1 Salvador Zubirán National Institute of Medical Science and Nutrition, Vasco de Quiroga 15, \\ Colonia Belisario Domínguez Sección XVI, Tlalpan, Mexico City 14080, Mexico; enrique.sotop@incmnsz.mx \\ 2 City of Hope Comprehensive Cancer Center, 1500 E Duarte Rd., Duarte, CA 91010, USA; \\ jv20384@usc.edu (J.V.); hekim@coh.org (H.K.); casun@coh.org (C.-L.S.); kecharle@health.ucsd.edu (K.C.); \\ acelis@coh.org (A.C.); vkatheria@coh.org (V.K.); danli@coh.org (D.L.); wdale@coh.org (W.D.) \\ * Correspondence: msedrak@coh.org; Tel.: +1-626-218-6200
}

Citation: Soto-Perez-de-Celis, E.; Vazquez, J.; Kim, H.; Sun, C.-L.; Charles, K.; Celis, A.; Katheria, V.; Li, D.; Dale, W.; Sedrak, M.S. Improving Care for Spanish-Speaking Older Adults with Breast Cancer: Feasibility, Reliability, and Validity of a Self-Administered Spanish Language Geriatric Assessment. Cancers 2021, 13, 2685. https:/ / doi.org/10.3390/cancers13112685

Academic Editor: Eduardo Bruera

Received: 16 April 2021

Accepted: 25 May 2021

Published: 29 May 2021

Publisher's Note: MDPI stays neutral with regard to jurisdictional claims in published maps and institutional affiliations.

Copyright: (c) 2021 by the authors. Licensee MDPI, Basel, Switzerland. This article is an open access article distributed under the terms and conditions of the Creative Commons Attribution (CC BY) license (https:// creativecommons.org/licenses/by/ $4.0 /)$.
Simple Summary: Conducting a geriatric assessment represents the standard of care for the management of older adults with cancer. However, most studies of the geriatric assessment in oncology have included non-Hispanic white populations with high educational levels living in developed countries. In this study, we assessed the feasibility, reliability, and validity of two methods of administration (electronic touchscreen tablet and paper/pencil) of the Spanish language version of a self-administered geriatric assessment among older women with breast cancer in the United States. Our results show that implementing a self-administered geriatric assessment using either an electronic tablet or paper/pencil is feasible, reliable, and valid in Spanish-speaking older adults. However, in order to complete the geriatric assessment, participants with lower educational levels were more likely to need help and took significantly longer to do so. This study highlights the importance of tailoring assessments and questionnaires to the cultural, social, and educational level of older adults with cancer.

Abstract: We evaluated the feasibility, reliability, and validity of a Spanish-language self-administered geriatric assessment (GA) in older (age $\geq 65$ ) Spanish-speaking women with breast cancer in the United States. Eligible participants $(n=181)$ were recruited and randomized. Feasibility was defined as the participant's unassisted GA completion rate, completion time, and perception on ease of completion. Reliability and validity were assessed using Spearman's correlation coefficients. Twosided $p<0.05$ was considered significant. Ninety-eight percent of participants $(n=177)$ completed the GA at least once. Median age was 70 years (range: $65-95$ ) and 55\% had $\leq 8$ th grade education. Forty-one percent $(n=73)$ were unable to complete the GA unassisted, median completion time was $28 \mathrm{~min}$ (range 8-90), and 77\% $(n=136)$ rated the GA as "easy" / very easy". Patients with $\leq 8$ th grade education took longer to complete the GA (30 vs. $25 \mathrm{~min}, p=0.0036$ ) and needed more assistance $(59 \%$ vs. $19 \%, p<0.001)$ than those with $\geq 9$ th grade education. Test-retest reliability was high $(\geq 0.82)$ for all domains except social activity (0.73). Validity among similar scales was found. The self-administered GA is a feasible, reliable, and valid tool for Spanish-speaking older women with breast cancer. Tailoring GA tools to the patients' educational level is important when implementing tools in multicultural environments.

Keywords: geriatric assessment; neoplasms; breast neoplasms; older adults; feasibility studies; validation study; hispanic americans; educational statu 


\section{Introduction}

Considerable global efforts have demonstrated the importance of incorporating the geriatric assessment (GA) as part of the routine care of older adults with cancer [1]. The GA is a multidimensional, comprehensive, and validated clinical tool that evaluates important domains for older adults, including physical function, comorbidity, cognition, nutritional status, polypharmacy, social support, and psychological status [2,3]. Evaluating older adults with cancer using the GA is useful in predicting treatment toxicity, estimating survival, and identifying areas of vulnerability that can be targeted with interventions [4-6].

Most studies assessing the feasibility and reliability of the GA in oncology have included older adults with cancer living in high-income countries, who are more likely to have higher health literacy and educational levels, and data regarding its use in populations from developing countries and/or with lower educational levels is lacking. While this is certainly relevant for the implementation of provider-administered GA tools, it is arguably even more so for self-administered assessments, which depend on the patient's ability to understand and answer questions correctly [7]. One of the first self-administered GA tools for oncology was developed by the Cancer and Aging Research Group (CARG) [8,9], who demonstrated that its implementation in both paper/pencil and electronic touchscreen formats was feasible, reliable, and valid among English-speaking older adults in the US [10]. While this self-administered GA has been translated into multiple languages, including Spanish, the feasibility and reliability of these translated versions is unknown.

Studying the validity of self-administered tools across languages and cultures is highly relevant. Among these, the cross-cultural validation of Spanish language tools is particularly important both for the evaluation of immigrants to high-income nations (4 million older adults in the US self-identify as Hispanic/Latino [11]) and for their implementation in Spanish-speaking countries worldwide. Therefore, the primary objective of this study was assessing the feasibility, reliability, and validity of the Spanish version of the CARG self-administered GA in Spanish-speaking older women with breast cancer living in the US, and the secondary objective was identifying the preferred method of delivering the GA (paper/pencil or electronic touchscreen).

\section{Materials and Methods}

\subsection{Study Population}

Participants were recruited from the outpatient breast cancer clinic at City of Hope, an NCI-designated comprehensive cancer center in Duarte, California between 22 February 2017 and 30 August 2019. Eligible participants were aged $\geq 65$ years, had a history of breast cancer (any stage, treatment, and time from diagnosis), and were fluent in Spanish (first or second language). Participants with any performance status could enroll; however, those with significant visual/hearing impairments precluding the ability to read the questions or hear instructions were ineligible. The study was approved by the City of Hope Institutional Review Board (reference number 16,335), and all participants provided written informed consent.

A total of 211 eligible patients were approached by the research team (Figure 1). Of these, $86 \%(n=181)$ agreed to participate. Reasons for refusal included disinterest $(n=15)$, concerns regarding ability to understand questions $(n=2)$, visual fatigue $(n=2)$, family members refusing on behalf of the patient $(n=5)$, and medical or cognitive condition $(n=6)$. Out of the 181 participants who agreed to participate, $98 \%(n=177)$ completed session 1 and were evaluable for feasibility outcomes, while $82 \%(n=150)$ completed both sessions 1 and 2 and were evaluable for reliability and validity outcomes. 


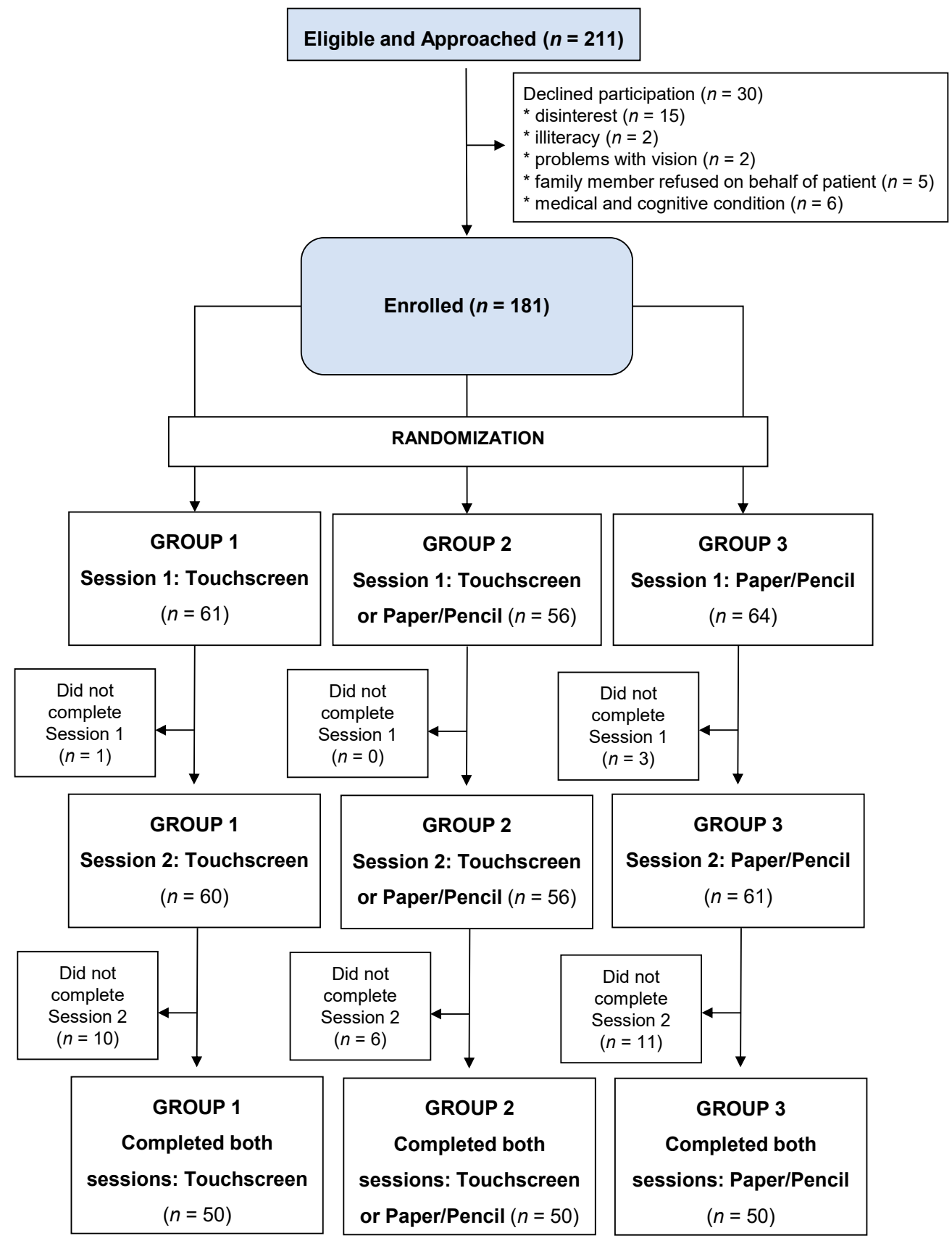

Figure 1. CONSORT diagram.

\subsection{Spanish Version of the Geriatric Assessment (GA)}

The English version of the GA was translated into Spanish, and its contents validated using the Functional Assessment of Chronic Illness Therapy (FACIT) Translation and Linguistic Validation Service. A full description of the utilized English-version GA, as well as the reliability and validity of each of its components, has been previously reported [2,3,8,9].

The GA consists of a self-administered portion completed by the patient, followed by a brief portion completed by a research team member evaluating cognition and physical performance. This study focused on the feasibility, reliability, and validity of the patient portion of the GA. The following measures were included in the GA used in this study: (1) Instrumental Activities of Daily Living (IADL) (subscale of the Older Americans Resources and Services [OARS] survey); (2) Activities of Daily Living (ADL) (subscale of Medical Outcomes Survey [MOS] Physical Health Measure); (3) Karnofsky Performance Status (KPS); (4) Number of falls in the past six months; (5) MOS Social Activity Limitations 
Measure; (6) number of comorbidities (OARS); (7) Mental Health Inventory (MHI-17); (8) MOS Social Support: emotional and tangible subscales; (9) Body Mass Index (BMI); and (10) cognition screening using the Blessed Orientation-Memory Concentration screening test (Table 1).

Table 1. Description of the various scales included in the Spanish Language Geriatric Assessment.

\begin{tabular}{|c|c|}
\hline Domain/Measure & Description \\
\hline \multicolumn{2}{|l|}{ Functional Status } \\
\hline $\begin{array}{l}\text { Instrumental Activities of Daily } \\
\text { Living (IADL) (subscale of OARS) }\end{array}$ & $\begin{array}{l}\text { Activities required to maintain independence in the community (meal preparation, } \\
\text { shopping, making telephone calls, money management). A higher score indicates less } \\
\text { need for assistance. } \\
\text { (Score range } 0-14 \text {; No. of items: } 7 \text { ) }\end{array}$ \\
\hline $\begin{array}{l}\text { Activities of Daily Living (ADL) } \\
\text { (subscale of MOS Physical Health) }\end{array}$ & $\begin{array}{l}\text { Wide range of physical functions (from bathing/dressing to vigorous activities such as } \\
\text { running). A higher score indicates a higher level of physical function. } \\
\text { (Score range } 0-100 \text {; No. of items: 10) }\end{array}$ \\
\hline $\begin{array}{l}\text { Karnofsky Performance Status } \\
\text { (KPS) (Patient-rated) }\end{array}$ & $\begin{array}{l}\text { Global indicator of patient function determined by patient self-report ranging from } \\
\text { normal to severely disabled. A higher score indicates a higher level of physical } \\
\text { function. (Score range } 0-100 ; \text { No. of item: } 1 \text { ) }\end{array}$ \\
\hline Number of falls in last 6 months & $\begin{array}{l}\text { Number of times patient has fallen in last six months } \\
\text { (No. of item: } 1 \text { ) }\end{array}$ \\
\hline $\begin{array}{l}\text { MOS Social Activity Limitations } \\
\text { Measure }\end{array}$ & $\begin{array}{l}\text { Ability to participate in social activities and degree to which health status limits } \\
\text { normal social activities. A higher score indicates a better level of social activity. } \\
\text { (Score range 0-100; No. of items: 4) }\end{array}$ \\
\hline \multicolumn{2}{|l|}{ Comorbid Medical Conditions } \\
\hline $\begin{array}{l}\text { Physical Health Section } \\
\text { (subscale of the OARS) }\end{array}$ & $\begin{array}{l}\text { Presence of comorbid illnesses. The score is the sum of the present comorbid } \\
\text { conditions. } \\
\text { (Score range } 0-13 \text {; No. of items: 13) }\end{array}$ \\
\hline \multicolumn{2}{|l|}{ Psychological State } \\
\hline Mental Health Inventory-17 (MHI-17) & $\begin{array}{l}\text { Measures the psychological state of patients regarding how the patient has been } \\
\text { feeling in the past two weeks. A higher score indicates better mental health. } \\
\text { (Score range } 0-100 ; \text { No. of items: 17) }\end{array}$ \\
\hline \multicolumn{2}{|r|}{ (2005) } \\
\hline $\begin{array}{l}\text { MOS Social Support: } \\
\text { Emotional and tangible subscales }\end{array}$ & $\begin{array}{l}\text { Perceived availability of social support. A higher score indicates better social support. } \\
\text { (Score range 0-100; No. of items: } 12 \text { ) }\end{array}$ \\
\hline $\begin{array}{l}\text { Nutritional Status } \\
\text { Body Mass Index (BMI) }\end{array}$ & BMI $\left(\mathrm{kg} / \mathrm{m}^{2}\right)=$ Weight $/$ height $^{2}$ \\
\hline \multicolumn{2}{|l|}{ Cognition } \\
\hline $\begin{array}{l}\text { Blessed } \\
\text { Orientation-Memory-Concentration }\end{array}$ & $\begin{array}{l}\text { Gross measure of cognitive function. A score of } 11 \text { or greater indicates potential } \\
\text { cognitive impairment. } \\
\text { (Score range } 0-28 \text {; No. of items: 6) }\end{array}$ \\
\hline \multicolumn{2}{|l|}{ Medications } \\
\hline Number of medications & $\begin{array}{l}\text { Number of medications including prescribed, herbal, and over-the-counter } \\
\text { medications. } \\
\text { (No. of item: 1) }\end{array}$ \\
\hline
\end{tabular}

Abbreviations: MOS, Medical Outcomes Study; OARS, Older American Resources and Services. Bold to signify different categories of the geriatric assessment.

\subsection{Study Procedure and Measures}

To assess feasibility and reliability, participants were asked to complete the Spanish version of the GA twice within the same day (sessions 1 and 2). To examine various methods of delivering the GA (electronic touchscreen tablet or paper/pencil), participants were randomized into one of three groups: group 1, completion of the touchscreen version in both sessions; group 2, completion of the touchscreen version and the paper/pencil version (random order); and group 3, completion of the paper/pencil version in both sessions.

In all groups, before starting session 1, participants were given a brief introduction about the GA. Patients randomized to the touchscreen method also received guidance on its use. Participants completed the GA in a quiet room within the clinic space. A Spanish- 
speaking research assistant or a certified Spanish translator was available if needed. Family members could be in the room with the participant and assist when needed.

At the end of each session, participants were asked to provide feedback about questions that were difficult to understand or perceived to be missing from the survey using open-ended questions; Likert-style items were utilized to assess their perception of the survey length ("too long", "too short", or "just right") and whether any of the questions were upsetting. Participants were asked to rate the difficulty level ("very easy", "easy", "difficult", or "very difficult") of the GA, their computer skill level (none, beginner, intermediate, or advanced), and to specify their preferred method of GA completion (touchscreen vs. paper/pencil).

Sociodemographic information was self-reported through a study-specific questionnaire which included age, primary language, marital status, educational level, employment status, income, and country of birth. The patient's breast cancer stage and prior treatment (surgery, radiation, chemotherapy, hormone therapy, and/or systemic therapy) was obtained from chart reviews.

\subsection{Statistical Analysis}

The feasibility of the Spanish version of the GA was evaluated among all patients who completed session $1(n=177)$. Feasibility was demonstrated through the following factors: (a) rate of completion of the GA, (b) rate of completion of the GA without assistance from research team members and/or family members, (c) number of questions missed/skipped or selected as "prefer not to answer" or "I don't know", (d) length of time needed to complete the GA, (e) patients' perception of the ease of completing the GA (rating it as "easy" /"very easy" to complete), and (f) patients' perception of how long it took to complete the GA.

Test-retest reliability for the same method and across methodologies (touchscreen vs. paper/pencil) was evaluated among the 150 participants who completed both sessions using Spearman correlation coefficients. The internal consistency of each component of the GA was analyzed using Cronbach's alpha coefficient across all surveys, including the three groups and both timepoints $(n=300)$. Spearman correlation coefficients among similar scales were assessed to determine scale validity.

For all analyses, summary statistics including frequencies and percentages were presented for categorical variables and medians with ranges for continuous variables. Chisquare tests/Fisher's exact method (for categorical variables) and Kruskal-Wallis tests (for continuous variables) were used for between-group comparisons. Feasibility and reliability were assessed for all participants and separately by method (touchscreen vs. paper/pencil). All analyses were performed using SAS 9.4 and a two-sided $p$-value $<0.05$ considered as statistically significant.

\section{Results}

\subsection{Patient Demographics and Disease Characteristics}

Participants had a median age of 70 years (range 65-95 years). All of them were women; $89 \%$ listed Spanish as their primary language and 78\% exclusively spoke Spanish at home (Table 2). Most participants were born outside the US, with $67 \%$ being from Mexico, 18\% from Central America and the Caribbean, and 7\% from South America. More than half of the participants (55\%) had $\leq 8$ th grade education and $33 \%$ had graduated high school and/or completed some post-high school education. Most participants were married (45\%), retired (52\%), and had an annual household income of $<\$ 50,000(83 \%)$. Most had early-stage breast cancer and had received prior treatment, including surgery, radiation, chemotherapy, and/or hormonal therapy. There were no significant differences between groups (all $p>0.05$ ). 
Table 2. Demographic and disease characteristics for all participants $(n=177)$.

\begin{tabular}{|c|c|c|c|c|}
\hline Variable & $\begin{array}{c}\text { Overall } \\
(n=177)\end{array}$ & $\begin{array}{l}\text { Group } 1 \text { Touchscreen } \\
(n=60)\end{array}$ & $\begin{array}{l}\text { Group } 2 \text { Touchscreen \& Paper/Pencil } \\
\qquad(n=56)\end{array}$ & $\begin{array}{l}\text { Group } 3 \text { Paper/Pencil } \\
(n=61)\end{array}$ \\
\hline \multicolumn{5}{|l|}{ Sociodemographic Variables } \\
\hline Age (Median, Range) & $70(65-95)$ & $68.5(65-88)$ & $70(65-95)$ & $70(65-87)$ \\
\hline \multicolumn{5}{|l|}{ Primary Language $(n(\%))$} \\
\hline Spanish & $158(89.3 \%)$ & $53(88.3 \%)$ & $50(89.3 \%)$ & $55(90.2 \%)$ \\
\hline English & $16(9.0 \%)$ & $6(10.0 \%)$ & $5(8.9 \%)$ & $5(8.2 \%)$ \\
\hline English and Spanish & $3(1.7 \%)$ & $1(1.7 \%)$ & $1(1.8 \%)$ & $1(1.6 \%)$ \\
\hline \multicolumn{5}{|l|}{ Language Spoken at Home $(n(\%))$} \\
\hline Spanish & $138(78.0 \%)$ & $50(83.3 \%)$ & $45(80.4 \%)$ & $43(70.5 \%)$ \\
\hline $\begin{array}{l}\text { English Only / English and Spanish } \\
\text { Country of Birth }(\boldsymbol{n}(\%))\end{array}$ & $39(22.0 \%)$ & $10(16.7 \%)$ & $11(19.6 \%)$ & $18(29.5 \%)$ \\
\hline Mexico & $119(67.2 \%)$ & $38(63.3 \%)$ & $42(75.0 \%)$ & $39(63.9 \%)$ \\
\hline Central America/Caribbean & $32(18.1 \%)$ & $12(20.0 \%)$ & $7(12.5 \%)$ & $13(21.3 \%)$ \\
\hline South America & $12(6.8 \%)$ & $5(8.3 \%)$ & $4(7.1 \%)$ & $3(4.9 \%)$ \\
\hline United States & $11(6.2 \%)$ & $4(6.7 \%)$ & $3(5.4 \%)$ & $4(6.6 \%)$ \\
\hline Missing & $3(1.7 \%)$ & $1(1.7 \%)$ & & $2(3.3 \%)$ \\
\hline Marital Status ( $n(\%))$ & & & & * \\
\hline Married or Domestic Partnership & $80(45.2 \%)$ & $29(48.3 \%)$ & $23(41.1 \%)$ & $28(45.9 \%)$ \\
\hline Widowed & $41(23.2 \%)$ & $16(26.7 \%)$ & $16(28.6 \%)$ & $9(14.8 \%)$ \\
\hline Divorced, Separated & $36(20.3 \%)$ & $8(13.3 \%)$ & $13(23.2 \%)$ & $15(24.6 \%)$ \\
\hline Never Married or Missing & $20(11.3 \%)$ & $7(11.7 \%)$ & $4(7.1 \%)$ & $9(14.8 \%)$ \\
\hline Educational Level $(n(\%))$ & * & $*$ & & \\
\hline 8th Grade or Less & $97(54.8 \%)$ & $32(53.3 \%)$ & $32(57.1 \%)$ & $33(54.1 \%)$ \\
\hline 9-11th Grade & $20(11.3 \%)$ & $7(11.7 \%)$ & $6(10.7 \%)$ & $7(11.5 \%)$ \\
\hline High School Graduate & $19(10.7 \%)$ & $10(16.7 \%)$ & $6(10.7 \%)$ & $3(4.9 \%)$ \\
\hline \multicolumn{5}{|l|}{ Bachelor's or Advanced } \\
\hline $\begin{array}{l}\text { Degree/Some College/Technical } \\
\text { College }\end{array}$ & $39(22.0 \%)$ & $10(16.7 \%)$ & $12(21.4 \%)$ & $17(27.9 \%)$ \\
\hline Did Not Answer & $2(1.1 \%)$ & $1(1.7 \%)$ & & $1(1.6 \%)$ \\
\hline \multicolumn{5}{|l|}{ Employment $(n(\%))$} \\
\hline Retired & $92(52.0 \%)$ & $34(56.7 \%)$ & $27(48.2 \%)$ & $31(50.8 \%)$ \\
\hline Homemaker & $44(24.9 \%)$ & $14(23.3 \%)$ & $15(26.8 \%)$ & $15(24.6 \%)$ \\
\hline Disabled/Unemployed/Other & $30(16.9 \%)$ & $9(15.0 \%)$ & $9(16.1 \%)$ & $12(19.7 \%)$ \\
\hline Employed & $11(6.2 \%)$ & $3(5.0 \%)$ & $5(8.9 \%)$ & $3(4.9 \%)$ \\
\hline \multicolumn{4}{|l|}{ Annual Household Income ( $n(\%))$} & $*$ \\
\hline$<\$ 25,000$ & $78(44.1 \%)$ & $24(40 \%)$ & $29(51.8 \%)$ & $25(41.0 \%)$ \\
\hline$\$ 25,000-\$ 50,000$ & $68(38.4 \%)$ & $21(35 \%)$ & $19(33.9 \%)$ & $28(45.9 \%)$ \\
\hline$>\$ 50,000$ & $23(13 \%)$ & $13(21.7 \%)$ & $6(10.7 \%)$ & $4(6.6 \%)$ \\
\hline Missing & $8(4.5 \%)$ & $2(3.3 \%)$ & $2(3.6 \%)$ & $4(6.6 \%)$ \\
\hline \multicolumn{5}{|l|}{$\begin{array}{l}\text { Clinical Characteristics } \\
\text { Prior Treatment }(n(\%))\end{array}$} \\
\hline Surgery & $147(83.1 \%)$ & $49(81.7 \%)$ & $46(82.1 \%)$ & $52(85.3 \%)$ \\
\hline Radiation & $99(55.9 \%)$ & $33(55.0 \%)$ & $30(53.6 \%)$ & $36(59.0 \%)$ \\
\hline Chemotherapy & $103(58.2 \%)$ & $36(60.0 \%)$ & $36(64.3 \%)$ & $31(50.8 \%)$ \\
\hline Hormone Therapy & $126(71.2 \%)$ & $41(68.3 \%)$ & $42(75.0 \%)$ & $43(70.5 \%)$ \\
\hline Targeted Therapy & $11(6.2 \%)$ & $6(10.0 \%)$ & $2(3.6 \%)$ & $3(4.9 \%)$ \\
\hline None & $9(5.1 \%)$ & $3(5.0 \%)$ & $4(7.1 \%)$ & $2(3.3 \%)$ \\
\hline \multicolumn{5}{|l|}{$\begin{array}{l}\text { Number of Prior Lines of } \\
\text { Chemotherapy }(n(\%))\end{array}$} \\
\hline 0 & $76(42.9 \%)$ & $24(40.0 \%)$ & $20(35.7 \%)$ & $32(52.4 \%)$ \\
\hline 1 & $78(44.1 \%)$ & $28(46.7 \%)$ & $28(50.0 \%)$ & $22(36.1 \%)$ \\
\hline $2+$ & $23(13.0 \%)$ & $8(13.3 \%)$ & $8(14.3 \%)$ & $7(11.5 \%)$ \\
\hline \multicolumn{5}{|l|}{ Stage ( $n(\%))$} \\
\hline 0 -III & $146(82.5 \%)$ & $46(76.7 \%)$ & 49 (87.5\%) & $51(83.6 \%)$ \\
\hline IV & $31(17.5 \%)$ & $14(23.3 \%)$ & $7(12.5 \%)$ & $10(16.4 \%)$ \\
\hline
\end{tabular}

* Percentages do not add up to 100 due to rounding. Bold to signify different categories.

\subsection{Feasibility}

Among the 177 participants who completed session 1, 87 used the touchscreen version of the GA and 90 the paper/pencil version (Table 3$)$. Fifty-nine percent $(n=104)$ were able to complete the GA on their own, without help from family members or research team members. Completion rates without requiring assistance were similar between touchscreen and paper/pencil methods ( $56 \%$ vs. $61 \%, p=0.52)$. Common reasons for needing assistance included difficulty understanding questions $(n=27)$, visual problems $(n=23)$, fatigue 
( $n=7)$, being uncomfortable with the technology/touchscreen format $(n=7)$, and literacy $(n=3)$. Participants with $\leq 8$ th grade educational level were more likely to need assistance than those with $\geq 9$ th grade educational level (59\% vs. $19 \%, p<0.001)$. Only one participant left a question unanswered using the touchscreen method, while 27 of those using the paper/pencil method left $\geq 1$ unanswered question (range 1-11, 15 missed one question, six missed two, one missed three, two missed four, one missed five, and two missed 11).

Table 3. Feasibility of the Spanish-Language Geriatric Assessment for the overall patient population and by method of administration (touchscreen and paper/pencil).

\begin{tabular}{|c|c|c|c|c|}
\hline & $\begin{array}{r}\text { Overall } \\
(n=177)\end{array}$ & $\begin{array}{l}\text { Touchscreen } \\
\quad(n=87)\end{array}$ & $\begin{array}{l}\text { Paper/Pencil } \\
\quad(n=90)\end{array}$ & $p$-Value \\
\hline$n(\%)$ completed without assistance & $104(58.8 \%)$ & $49(56.3 \%)$ & $55(61.1 \%)$ & 0.52 \\
\hline$n(\%)$ patients missed any questions & $28(15.8 \%)$ & $1(1.1 \%)$ & $27(30.0 \%)$ & $<0.0001$ * \\
\hline \multicolumn{5}{|l|}{ Time to Finish the GA } \\
\hline Median (Range) & $28(8-90)$ & $28(8-78)$ & $28(12-90)$ & \multirow{2}{*}{$0.74^{* *}$} \\
\hline Mean (SD) & $31.6(14.0)$ & $32.1(14.3)$ & $31.2(13.8)$ & \\
\hline \multicolumn{5}{|l|}{ Easiness to Complete GA } \\
\hline \% Easy/Very Easy & $136(76.8 \%)$ & $63(72.4 \%)$ & $73(81.1 \%)$ & 0.17 \\
\hline \multicolumn{5}{|l|}{ Perception of Time Needed to Complete the } \\
\hline Too Long & $29(16.4 \%)$ & $15(17.2 \%)$ & $14(15.6 \%)$ & \multirow{4}{*}{0.96} \\
\hline Just Right & $135(76.3 \%)$ & $66(75.9 \%)$ & $69(76.7 \%)$ & \\
\hline Too Short & $10(5.6 \%)$ & $5(5.8 \%)$ & $5(5.6 \%)$ & \\
\hline No Answer & $3(1.7 \%)$ & $1(1.2 \%)$ & $2(2.2 \%)$ & \\
\hline \multicolumn{5}{|l|}{ Computer Skill } \\
\hline None & $111(62.7 \%)$ & $51(58.6 \%)$ & $60(66.7 \%)$ & \multirow{5}{*}{$0.19 *$} \\
\hline Beginner & $40(22.6 \%)$ & $25(28.7 \%)$ & $15(16.7 \%)$ & \\
\hline Intermediate & $23(13.0 \%)$ & $11(12.6 \%)$ & $12(13.3 \%)$ & \\
\hline Advanced & 0 & 0 & 0 & \\
\hline No Answer & $3(1.7 \%)$ & & $3(3.3 \%)$ & \\
\hline \multicolumn{5}{|l|}{ Preferred GA Administration Method } \\
\hline Paper/Pencil & $93(52.6 \%)$ & $37(42.5 \%)$ & $56(62.2 \%)$ & \multirow{3}{*}{0.005} \\
\hline Touchscreen & $82(46.3 \%)$ & $50(57.5 \%)$ & $32(35.6 \%)$ & \\
\hline No Answer & $2(1.1 \%)$ & & $2(2.2 \%)$ & \\
\hline
\end{tabular}

Abbreviations: GA: geriatric assessment, SD: standard deviation. * $p$-value were obtained from Fisher's exact test. ** $p$-value was obtained from Kruskal-Wallis test. All other $p$-values were obtained from chi-square test and "No Answer" category was not included. Bold to signify different categories.

\subsubsection{Completion Time}

Median time to complete the GA was $28 \mathrm{~min}$ (range 8-90 min). No differences were observed between the two methods (Table 3; Figure 2). Participants with $\leq 8$ th grade educational level took significantly longer to complete the GA than those with a $\geq 9$ th grade educational level (median 30 vs. $25 \mathrm{~min}, p=0.004$ ).

\subsubsection{Satisfaction with the GA}

Most (76\%) of the participants thought the length of the GA was "just right" and the majority (77\%) rated the GA as "easy" / "very easy" to complete. Again, no significant differences were observed between the two methods (Table 3). Most participants rated their computer skill level as none/beginner (85\%), with none of them rating it as "advanced". Among those who were randomized to the touchscreen method, more than half $(58 \%)$ preferred touchscreen technology. However, among those who were randomized to the paper/pencil method, only 36\% preferred using touchscreen technology $(p=0.005)$.

\subsection{Reliability and Validity}

One-hundred-and-fifty patients completed both sessions, 50 in each of the three groups (Figure 1). The reliability of the following measures was evaluated and presented in Table 4: IADL; ADL; KPS; MHI-17; MOS Social Activity Limitations Measure; and MOS Social Sup- 
port. Internal consistency as measured by the Cronbach Alpha in all the surveys completed by the three groups at both timepoints $(n=300)$ was good for all measures $(\geq 0.88)$, except for MOS Social Activity Limitations Measure (0.68). The test-retest reliability (measured using Spearman's rank correlation coefficient) of all six scales within the same method (touchscreen and paper/pencil) and across methodologies (touchscreen vs. paper/pencil) was strong ( $>0.8)$ except for MOS Social Activity Limitations Measure $(>0.7)$.

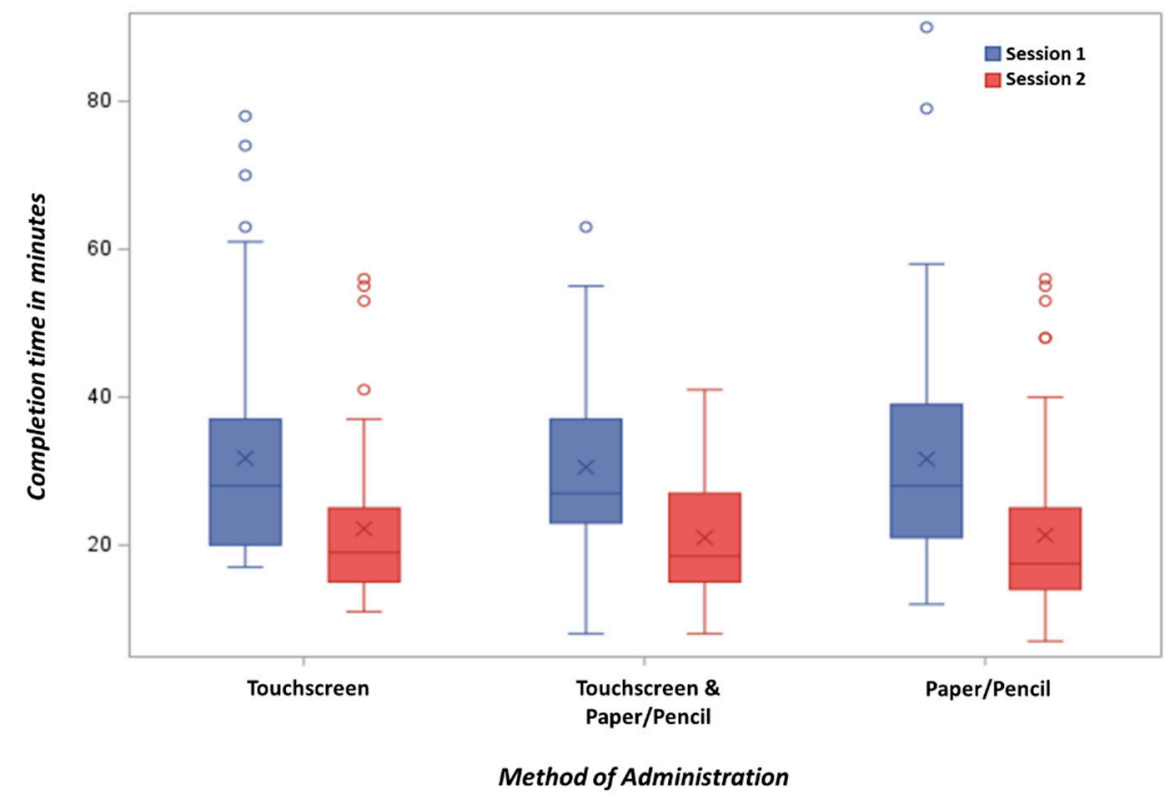

Figure 2. Distribution of completion time for the Spanish-Language Geriatric Assessment by Group. $\mathrm{X}$ represents the mean and the horizontal line inside the box represents the median.

Table 4. Internal consistency and test-retest reliability of selected measures included in the Self-Administered SpanishLanguage Geriatric Assessment.

\begin{tabular}{|c|c|c|c|c|c|c|}
\hline \multirow{2}{*}{ Scale } & \multirow{2}{*}{$\begin{array}{l}\text { Raw Cronbach Alpha } \\
\text { All Completed Surveys } \\
\qquad(n=300)\end{array}$} & \multirow{2}{*}{$\begin{array}{c}\text { Standardized } \\
\text { Cronbach Alpha } \\
\text { All Completed } \\
\text { Surveys } \\
(n=300)\end{array}$} & \multicolumn{4}{|c|}{$\begin{array}{l}\text { Test-Retest } \\
\text { Reliability Spearman Rank Correlation Coefficient }\end{array}$} \\
\hline & & & $\begin{array}{l}\text { Overall } \\
(n=150)\end{array}$ & $\begin{array}{l}\text { Touchscreen } \\
\quad(n=50)\end{array}$ & $\begin{array}{l}\text { Paper/Pencil \& } \\
\text { Touchscreen } \\
(n=50)\end{array}$ & $\begin{array}{l}\text { Paper/Pencil } \\
\quad(n=50)\end{array}$ \\
\hline IADL & 0.88 & 0.88 & 0.93 & 0.93 & 0.95 & 0.91 \\
\hline ADL & 0.93 & 0.93 & 0.94 & 0.93 & 0.96 & 0.92 \\
\hline KPS * & & & 0.82 & 0.81 & 0.89 & 0.75 \\
\hline MHI & 0.93 & 0.93 & 0.88 & 0.89 & 0.81 & 0.88 \\
\hline Social Activity ${ }^{\dagger}$ & 0.68 & 0.69 & 0.73 & 0.72 & 0.72 & 0.76 \\
\hline Social Support $\ddagger$ & 0.96 & 0.96 & 0.85 & 0.82 & 0.80 & 0.93 \\
\hline
\end{tabular}

Abbreviations: IADL: Instrumental Activities of Daily Living; ADL: Activities of Daily Living; KPS: Karnofsky Performance Status; MHI: Mental Health Inventory-17. ${ }^{*}$ KPS only has one question so Cronbach Alpha does not apply. ${ }^{\dagger}$ Medical Outcomes Study Social Activity Limitations Measure. $¥$ Medical Outcomes Study Social Support Survey: Emotional and Tangible subscales.

The validity of the GA was evaluated for the overall cohort and for each method (Table 5). Correlations between IADL and ADL scores were strong overall (0.75) and $>0.72$ for all groups. The patient's assessment of Karnofsky Performance Status (KPS) correlated weakly with the IADL score (0.63) and with the patient's social activity level (0.47). The MOS Social Activity Limitations score was weakly correlated with ADL (0.55) and IADL (0.47) score. 
Table 5. Geriatric assessment scale validity.

\begin{tabular}{ccccc}
\hline & $\begin{array}{c}\text { Overall } \\
(\boldsymbol{n}=\mathbf{1 5 0 )}\end{array}$ & $\begin{array}{c}\text { Touchscreen } \\
(\boldsymbol{n}=\mathbf{5 0 )}\end{array}$ & $\begin{array}{c}\text { Touchscreen \& } \\
\text { Paper/Pencil } \\
(\boldsymbol{n}=\mathbf{5 0 )}\end{array}$ & $\begin{array}{c}\text { Paper/Pencil } \\
(\boldsymbol{n}=\mathbf{5 0 )}\end{array}$ \\
\hline IADL with ADL & 0.75 & Spearman Rank Correlation Coefficient \\
IADL with KPS & 0.63 & 0.73 & 0.75 & 0.72 \\
IADL with Social Activity & 0.47 & 0.65 & 0.69 & 0.51 \\
ADL with KPS & 0.71 & 0.54 & 0.47 & 0.41 \\
ADL with Social Activity & 0.55 & 0.63 & 0.82 & 0.66 \\
KPS with Social Activity & 0.51 & 0.63 & 0.52 & 0.55 \\
\hline
\end{tabular}

Abbreviations: IADL: Instrumental Activities of Daily Living; ADL: Activities of Daily Living; KPS: Karnofsky Performance Status (patient-reported).

\section{Discussion}

The Spanish language version of the CARG self-administered GA is feasible, reliable, and valid for obtaining data regarding the relevant geriatric domains among Spanishspeaking older women with breast cancer in the US, both in its touchscreen and paper/pencil version. Most participants were able to complete the GA, and over half were able to do so unassisted, with a median completion time of $<30 \mathrm{~min}$. Furthermore, threequarters rated the GA as "easy" or "very easy" to complete, and most were satisfied with its length. No significant differences in completion times were found between the touchscreen and paper/pencil methods, and both were reliably consistent. Importantly, participants with $\geq 9$ th grade education needed less assistance and completed the GA tool faster. The touchscreen method was better at avoiding missed questions, and participants who were exposed to it expressed their preference towards touchscreen technology.

Developing GA tools in Spanish is essential to assess older Spanish-speaking immigrants to high-income nations such as the US, as well as for improving access to geriatric oncology care in low- and middle-income nations in Latin America and the Caribbean. Spanish is the fourth most widely spoken language in the world, with over 500 million speakers, and is the official language of 20 countries in four continents [12]. In addition, it is the most spoken unofficial language in the US, with $13.5 \%$ of the US population speaking Spanish at home [13]. Increasing the availability of tools that can be utilized to assess patients in their own language is of the utmost importance for reducing inequities in access to care, including a lack of access to a GA as part of the cancer care of older adults.

However, there are several caveats that must be considered when trying to translate and implement self-administered surveys. This can be shown by analyzing the contrasts between our current findings and our previously published study examining the feasibility, reliability, and validity of the English-language version of the CARG self-administered GA. In that study, where nearly $80 \%$ of respondents were non-Hispanic white, the median time to complete the GA was $\leq 21$ min depending on methodology, and $<10 \%$ of participants needed assistance [10]. We believe that the differences in findings with the present study may be explained by social, economic, and educational factors, rather than by ethnicity or language. In the present study, only $34 \%$ of participants had high school or higher education, compared with $96 \%$ of participants in the English-language feasibility study. This closely reflects the real-world circumstances of older Hispanic adults in the US, who often have lower educational levels than their non-Hispanic white counterparts, which may be a direct consequence of the low educational coverage in their countries of origin $[14,15]$. For example, among older adults in Mexico, the mean number of years of schooling is of 4.6 [16]. Therefore, validation studies of self-administered assessments among older individuals from diverse racial/ethnic backgrounds often beg consideration of the target population's education level [17]. This is clearly shown in our study, as participants with higher educational levels needed significantly less assistance and completed the assessment faster than those with lower educational levels. Other studies have shown similar results, for example while patients from high-income nations (Australia, Japan, 
Western Europe, and the US) took a median of $11 \mathrm{~min}$ to complete the EORTC-QLQC30 quality of life questionnaire [18], Mexican women (65\% with elementary school education or less) required almost double the time (median $19.5 \mathrm{~min}$ ) [19]. Strategies to assist lowliteracy respondents answer self-administered questionnaires include simplifying the language of written materials, using shorter questionnaires, including illustrations and/or graphics, and limiting "sensitive" items [20,21]. However, even materials designed for fifth-grade reading level might be difficult to understand by many patient populations [21].

The reliability and validity of the measures included in this GA have been established by previous studies $[2,3,10,22]$. This study confirms that the Spanish-language scales are internally consistent and reliable in terms of test-retest within and across methodologies. The IADL score correlated with the ADL score, demonstrating validity as both assess daily function. In addition, our results demonstrate that the Spanish version of the CARG GA is not only reliable in terms of repeated testing, but also consistent across methods of implementation (touchscreen vs. paper/pencil). Although touchscreen technology may lead to fewer missed answers, most participants still preferred more traditional paper/pencil surveys. This might be related to the limited experience with the utilization of touchscreen technologies among older Hispanic adults ( $85 \%$ of the participants in our study said they had no computer skills or were beginners), with $<40 \%$ of Americans aged $\geq 70$ reporting owning a tablet as of 2020 . Interestingly, most participants randomized to the touchscreen version of the GA reported preferring using a tablet over paper/pencil, showing how older adults who are exposed to technology and receive guidance on how to use it are likely to embrace it [23].

There are limitations to this research. First, our sample consisted mostly of women from Mexico, with limited representation of individuals from the Caribbean, Central, and South America. Considering the differences in the Spanish language across countries, it is possible our results may have been different with another sample. However, as greater than half of Hispanics living in the US have Mexican origins, we believe ours to be a reasonably representative sample of Spanish-speaking Americans in southern California [24]. Second, our GA captured if a patient had $<9$ th grade educational level, but a more detailed breakdown regarding education level and health literacy would have provided more information for future clinical application. In addition, while patients were given instructions on how to use the touchscreen methodology, some patients still needed assistance completing the touchscreen GA. The availability of personnel for instruction and extra assistance needs to be considered when planning to utilize an electronic GA. Despite these limitations, this study also has several strengths. Previous studies of self-administered GA tools in oncology included a largely white, non-Hispanic, and college-educated population that may already be comfortable using the touchscreen methodology and understanding the survey items [8-10]. This study shows that using self-administered GA tools in oncology might be feasible among older adults with lower educational levels, and also presents researchers with future opportunities for tailoring GA strategies to fit diverse populations.

\section{Conclusions}

This study demonstrates that the Spanish version of the CARG self-administered GA is reliable and consistent in both its touchscreen and paper/pencil format. While the implementation of the GA is also feasible, older adults with lower educational levels may require assistance to complete it. Our results highlight the need for the development, transcultural adaptation, and tailoring of tools for older populations with differing cultural backgrounds, health literacy, and educational levels. As the field of geriatric oncology moves forward and becomes part of everyday oncology practice, research exploring strategies for mitigating racial, ethnic, and social disparities in access to the GA and to GA-guided care, such as the one we report, should take center stage. 
Author Contributions: Conceptualization, E.S.-P.-d.-C.; Methodology, C.-L.S., H.K., and E.S.-P.-d.-C.; Formal Analysis, C.-L.S. and H.K.; Investigation, E.S.-P.-d.-C., J.V., A.C., V.K., and K.C.; Resources, W.D., M.S.S., and D.L.; Data Curation, H.K.; Writing-Original Draft Preparation, E.S.-P.-d.-C., J.V. and H.K.; Writing-Review and Editing, E.S.-P.-d.-C., J.V., A.C., V.K., K.C, M.S.S., W.D. and D.L; Supervision, W.D., M.S.S., and D.L.; Project Administration, V.K.. All authors have read and agreed to the published version of the manuscript.

Funding: This research was funded by the Breast Cancer Research Foundation to Arti Hurria, the original principal investigator of the study. This work was also supported in part by the National Institute on Aging K24 AG055693 (PI: William Dale) and City of Hope's Center for Cancer and Aging. Enrique Soto-Perez-de-Celis received support from the Conquer Cancer Foundation of the American Society of Clinical Oncology 2016 Long-Term International Fellowship.

Institutional Review Board Statement: The study was conducted according to the guidelines of the Declaration of Helsinki and approved by the Institutional Review Board of City of Hope (protocol: City of Hope IRB\#16335; approval date: 27 October 2016).

Informed Consent Statement: Informed consent was obtained from all subjects involved in the study.

Data Availability Statement: The data presented in this study are available on request from the corresponding author.

Acknowledgments: Arti Hurria conceptualized the study with Soto-Perez-de-Celis, obtained funding, and supervised data acquisition and preliminary analysis, but died suddenly prior to the drafting of this manuscript summarizing primary results. We dedicate this manuscript to her legacy and mentorship.

Conflicts of Interest: Li reports research funding to his institution from Brooklyn Immunotherapeutics and AstraZeneca. He serves as a consultant and has received honoraria from Lexicon, TerSera Therapeutics, Ipsen, Eisai, Exelixis, Advanced Accelerator Applications, Bayer, Genentech, Taiho, Coherus, Sun Pharma, QED, and Merck, all outside the submitted work. The remaining authors declare no conflicts of interest. The funders had no role in the design of the study; in the collection, analyses, or interpretation of data; in the writing of the manuscript; or in the decision to publish the results.

\section{References}

1. Mohile, S.G.; Dale, W.; Somerfield, M.R.; Schonberg, M.A.; Boyd, C.M.; Burhenn, P.S.; Canin, B.; Cohen, H.J.; Holmes, H.M.; Hopkins, J.O.; et al. Practical Assessment and Management of Vulnerabilities in Older Patients Receiving Chemotherapy: ASCO Guideline for Geriatric Oncology. J. Clin. Oncol. 2018, 36, 2326-2347. [CrossRef] [PubMed]

2. Hurria, A.; Cirrincione, C.T.; Muss, H.B.; Kornblith, A.B.; Barry, W.; Artz, A.S.; Schmieder, L.; Ansari, R.; Tew, W.P.; Weckstein, D.; et al. Implementing a geriatric assessment in cooperative group clinical cancer trials: CALGB 360401. J. Clin. Oncol. 2011, 29, 1290-1296. [CrossRef] [PubMed]

3. Hurria, A.; Gupta, S.; Zauderer, M.; Zuckerman, E.L.; Cohen, H.J.; Muss, H.; Rodin, M.; Panageas, K.S.; Holland, J.C.; Saltz, L.; et al. Developing a cancer-specific geriatric assessment: A feasibility study. Cancer 2005, 104, 1998-2005. [CrossRef] [PubMed]

4. Li, D.; Sun, C.-L.; Kim, H.; Chung, V.; Koczywas, M.; Fakih, M.; Chao, J.; Chien, L.; Charles, K.; Hughes, S.F.D.S.; et al. Geriatric assessment-driven intervention (GAIN) on chemotherapy toxicity in older adults with cancer: A randomized controlled trial. J. Clin. Oncol. 2020, 38 (Suppl. 15), 12010. [CrossRef]

5. Mohile, S.G.; Mohamed, M.R.; Culakova, E.; Xu, H.; Loh, K.P.; Magnuson, A.; Flannery, M.A.; Ramsdale, E.E.; Dunne, R.F.; Gilmore, N.; et al. A geriatric assessment (GA) intervention to reduce treatment toxicity in older patients with advanced cancer: A University of Rochester Cancer Center NCI community oncology research program cluster randomized clinical trial (CRCT). J. Clin. Oncol. 2020, 38 (Suppl. 15), 12009. [CrossRef]

6. Wildiers, H.; Heeren, P.; Puts, M.; Topinkova, E.; Janssen-Heijnen, M.L.; Extermann, M.; Falandry, C.; Artz, A.; Brain, E.; Colloca, G.; et al. International Society of Geriatric Oncology consensus on geriatric assessment in older patients with cancer. J. Clin. Oncol. 2014, 32, 2595-2603. [CrossRef] [PubMed]

7. Beaton, D.E.; Bombardier, C.; Guillemin, F.; Ferraz, M.B. Guidelines for the process of cross-cultural adaptation of self-report measures. Spine 2000, 25, 3186-3191. [CrossRef] [PubMed]

8. Hurria, A.; Mohile, S.; Gajra, A.; Klepin, H.; Muss, H.; Chapman, A.; Feng, T.; Smith, D.; Sun, C.L.; De Glas, N.; et al. Validation of a Prediction Tool for Chemotherapy Toxicity in Older Adults With Cancer. J. Clin. Oncol. 2016, 34, 2366-2371. [CrossRef] [PubMed]

9. Hurria, A.; Togawa, K.; Mohile, S.G.; Owusu, C.; Klepin, H.D.; Gross, C.P.; Lichtman, S.M.; Gajra, A.; Bhatia, S.; Katheria, V.; et al. Predicting chemotherapy toxicity in older adults with cancer: A prospective multicenter study. J. Clin. Oncol. 2011, 29, 3457-3465. [CrossRef] [PubMed] 
10. Hurria, A.; Akiba, C.; Kim, J.; Mitani, D.; Loscalzo, M.; Katheria, V.; Koczywas, M.; Pal, S.; Chung, V.; Forman, S.; et al. Reliability, Validity, and Feasibility of a Computer-Based Geriatric Assessment for Older Adults with Cancer. J. Oncol. Pract. 2016, 12, e1025-e1034. [CrossRef] [PubMed]

11. U.S. Census Bureau. Population 65 Years and Over in the United States. 2017. Available online: https:/ / data.census.gov/cedsci/ table $? \mathrm{q}=65 \&$ table $=$ S0103\&tid=ACSST1Y2017.S0103\&hidePreview $=$ true\&tm $=$ false (accessed on 6 April 2021).

12. Ethnologue: Languages of the World, 24th ed.; Eberhard, D.M.; Simons, G.F.; Fennig, C.D. (Eds.) SIL International: Dallas, TX, USA, 2021; Available online: http:/ / www.ethnologue.com (accessed on 8 April 2021).

13. U.S. Census Bureau. 2015-2019 American Community Survey 5-Year Estimates. Available online: https://data.census.gov/ cedsci/table?q=language\&tid=ACSST1Y2019.S1601\&hidePreview=false (accessed on 6 April 2021).

14. U.S. Census Bureau. Educational Attainment in the United States: 2015. Available online: https://www.census.gov/content/ dam/Census/library/publications/2016/demo/p20-578.pdf (accessed on 6 April 2021).

15. U.S. Census Bureau. Educational Attainment in the United States: 2018. Available online: https://www.census.gov/data/tables/ 2018/demo/education-attainment/cps-detailed-tables.html (accessed on 6 April 2021).

16. Mexico Gobierno de la Republica. Situación de las Personas Adultas Mayores en México. Available online: http://cedoc. inmujeres.gob.mx/documentos_download/101243_1.pdf (accessed on 6 April 2021).

17. Lee, S.Y.; Bender, D.E.; Ruiz, R.E.; Cho, Y.I. Development of an easy-to-use Spanish Health Literacy test. Health Serv. Res. 2006, 41, 1392-1412. [CrossRef] [PubMed]

18. Aaronson, N.K.; Ahmedzai, S.; Bergman, B.; Bullinger, M.; Cull, A.; Duez, N.J.; Filiberti, A.; Flechtner, H.; Fleishman, S.B.; de Haes, J.C.; et al. The European Organization for Research and Treatment of Cancer QLQ-C30: A quality-of-life instrument for use in international clinical trials in oncology. J. Natl. Cancer Inst. 1993, 85, 365-376. [CrossRef] [PubMed]

19. Cerezo, O.; Onate-Ocana, L.F.; Arrieta-Joffe, P.; Gonzalez-Lara, F.; Garcia-Pasquel, M.J.; Bargallo-Rocha, E.; Vilar-Compte, D. Validation of the Mexican-Spanish version of the EORTC QLQ-C30 and BR23 questionnaires to assess health-related quality of life in Mexican women with breast cancer. Eur. J. Cancer Care 2012, 21, 684-691. [CrossRef] [PubMed]

20. Fredrickson, D.D.; Jones, T.L.; Molgaard, C.A.; Carman, C.G.; Schukman, J.; Dismuke, S.E.; Ablah, E. Optimal design features for surveying low-income populations. J. Health Care Poor Underserved 2005, 16, 677-690. [CrossRef] [PubMed]

21. Weiner, J.; Aguirre, A.; Ravenell, K.; Kovath, K.; McDevit, L.; Murphy, J.; Asch, D.A.; Shea, J.A. Designing an illustrated patient satisfaction instrument for low-literacy populations. Am. J. Manag. Care 2004, 10, 853-860. [PubMed]

22. Fillenbaum, G.G.; Smyer, M.A. The development, validity, and reliability of the OARS multidimensional functional assessment questionnaire. J. Gerontol. 1981, 36, 428-434. [CrossRef] [PubMed]

23. Vaportzis, E.; Giatsi Clausen, M.; Gow, A.J. Older Adults Experiences of Learning to Use Tablet Computers: A Mixed Methods Study. Front. Psychol. 2018, 9, 1631. [CrossRef] [PubMed]

24. U.S. Census Bureau. The Hispanic Population: 2010. Available online: https://www.census.gov/content/dam/Census/library/ publications/2011/dec/c2010br-04.pdf (accessed on 6 April 2021). 